\title{
Single-center analysis of appendiceal neoplasms
}

\author{
TAKAYUKI TAJIMA ${ }^{1}$, TAKUMA TAJIRI ${ }^{2}$, MASAYA MUKAI $^{3}$, TOMOKO SUGIYAMA $^{2}$, SAYURI HASEGAWA $^{3}$, \\ SOUICHIROU YAMAMOTO ${ }^{1}$, SOTARO SADAHIRO ${ }^{1}$, HIDEO SHIMADA ${ }^{4}$ and HIROYASU MAKUUCHI ${ }^{1,3}$ \\ ${ }^{1}$ Department of Surgery, Tokai University School of Medicine, Isehara, Kanagawa 259-1193; \\ Departments of ${ }^{2}$ Pathology and ${ }^{3}$ Surgery, Tokai University Hachioji Hospital, Hachioji, Tokyo 192-0032; \\ ${ }^{4}$ Department of Surgery Tokai University Oiso Hospital, Oiso, Kanagawa 259-0198, Japan
}

Received October 11, 2016; Accepted January 12, 2018

DOI: $10.3892 / \mathrm{ol} .2018 .8134$

\begin{abstract}
The purpose of the present study was to evaluate the recent trend of diagnosing appendiceal diseases through the analysis of appendectomy materials, stressing the importance of their pathological examination. A clinicopathological assessment of patients undergoing an appendectomy was conducted, based on the pathological examination of resected appendiceal lesions. Using a pathological database of surgical specimens from patients who underwent an appendectomy between March 2002 and September 2014, a retrospective, single-center analysis was performed. Among the 803 patients identified, 752 with appendiceal disease were selected for clinicopathological analysis. The diagnosis was inflammation (i.e. appendicitis) in $97.7 \%(n=735)$ and appendiceal neoplasm in $2.3 \%(n=17)$ of the patients. The most frequent type of appendiceal neoplasm was an intramucosal neoplasm $(23.5 \%, n=4)$. In conclusion, the incidence of appendiceal neoplasms has increased in recent years, potentially due to increased and earlier detection by newer imaging modalities.
\end{abstract}

\section{Introduction}

Appendiceal diseases, including appendicitis, are a common cause for emergency abdominal surgery, and appendiceal neoplasms are identified during surgery in $0.7-5 \%$ of patients $(1,2)$. A relatively recent development has been the incidental detection of appendiceal lesions during the follow-up of patients for other conditions, or during routine health screenings. These discoveries have increased in frequency due to the increased use of abdominal ultrasonography, computed tomography (CT), Positron emission

Correspondence to: Dr Takayuki Tajima, Department of Surgery, Tokai University School of Medicine, 143 Shimokasuya, Isehara, Kanagawa 259-1193, Japan

E-mail: takayukitajima1970@yahoo.co.jp

Key words: appendiceal neoplasm, low-grade appendiceal mucinous neoplasm, vermiform appendix, single institution in Japan, computed tomography tomography (PET/CT) and serum tumor markers for patient follow-up and screening $(3,4)$. However, surgeons do not always submit appendectomy specimens for pathological examination, allowing tumors to go undiagnosed despite surgical treatment (5). Consequently, there has been an increase in the number of studies describing recurrent neoplasms in the appendiceal remnant (6). Accordingly, surgeons are becoming increasingly aware of the importance of obtaining a pathological confirmation of the diagnosis in patients treated surgically for appendicitis-like symptoms (7).

In addition to lower birth rates, medical advances and expanded health screenings have resulted in an aging Japanese population, and novel therapies have increased the number of immunocompromised patients (8). There has also been an increase in international visitors with Amoeba-associated infectious disease $(9,10)$. These factors may have contributed to the pattern of appendiceal disease in Japan; however, during the past 25 years there has been no single-center investigation of the incidence or types of appendiceal neoplasms in patients undergoing a total appendectomy (11). The most recent report was based on nationwide data from multiple institutions, and thus did not provide information regarding clinical patterns at a local level, due to the indications for appendectomy and the resulting disease statistics varying between institutions (5). To determine whether the pattern of appendiceal disease is changing, a retrospective single-center study that assessed the incidence and age distribution of appendiceal diseases was conducted in the present study, in order to understand the clinical implications for patients undergoing an appendectomy.

\section{Patients and methods}

Ethical approval. The study was approved by the institutional review board of Tokai University Hachioji Hospital (Hachioji, Japan; approval no. R14-242). Informed consent for the appendectomy was obtained from the patients and/or family members.

Patient selection. Radical appendectomies/ileocecal resections were performed without attempting conservative therapies, including antimicrobial agents, if an abdominal CT or ultrasound identified an appendiceal lesion. By reviewing the pathological database of the appendectomy specimens 
A

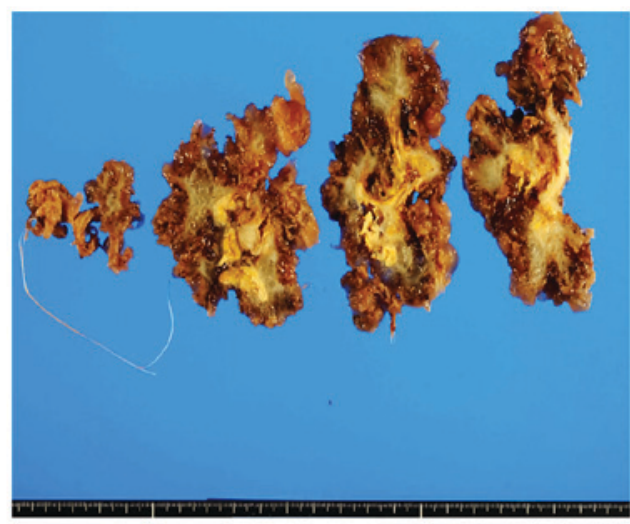

C

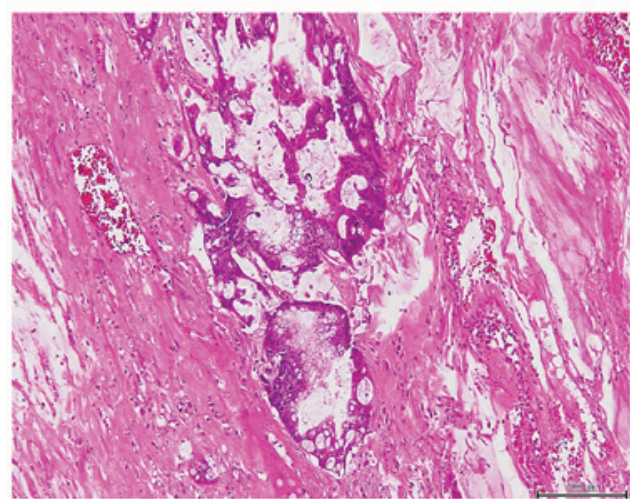

B

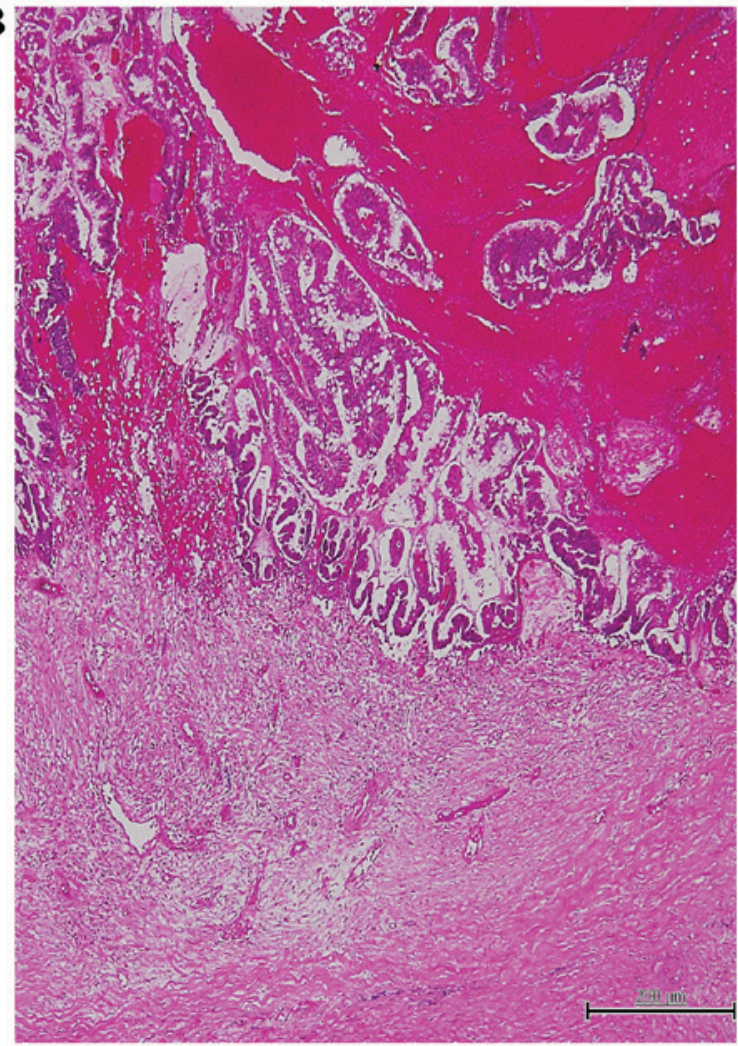

Figure 1. Representative case of a mucinous adenocarcinoma with high-grade pseudomyxoma peritonei from patient 9 (A) Macroscopic and (B) histological findings for the mucinous adenocarcinoma. (C) Histological findings from the high-grade pseudomyxoma peritonei.

A

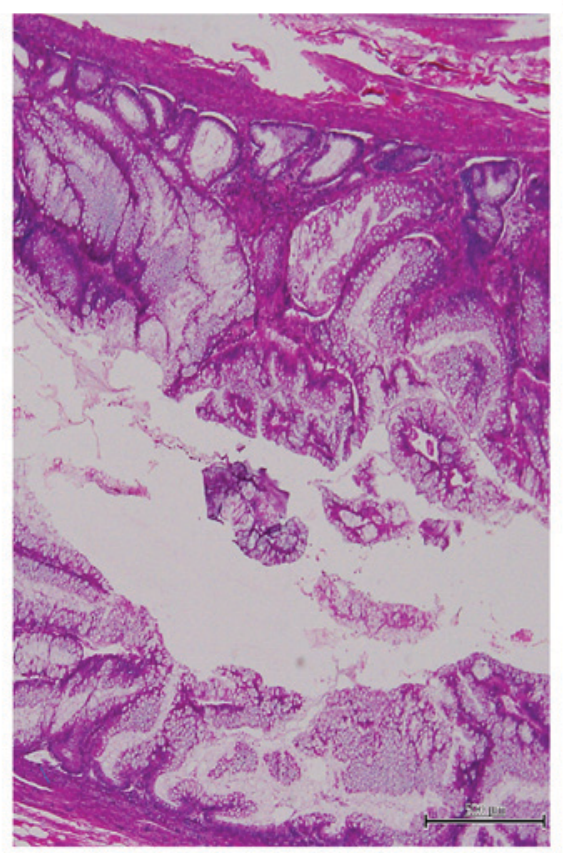

B

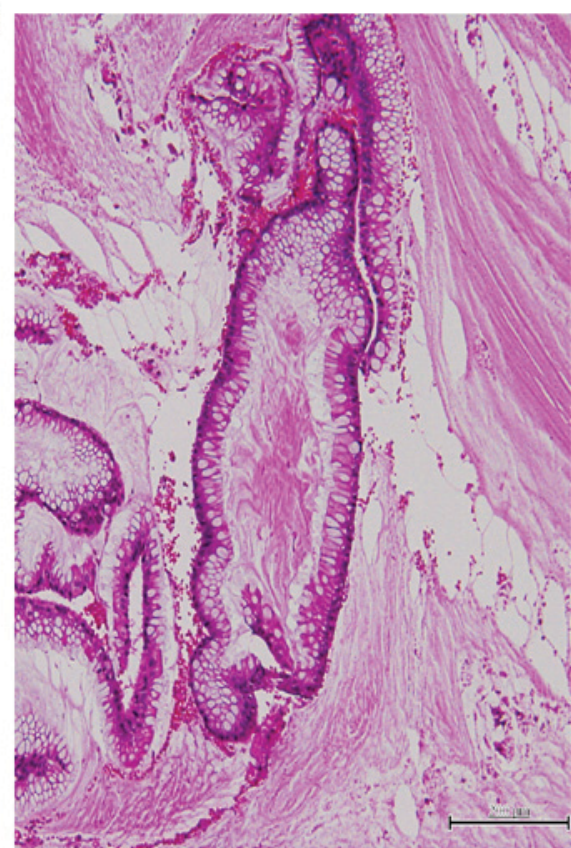

Figure 2. Representative case of a low-grade appendiceal mucinous neoplasm with low-grade pseudomyxoma peritonei in patient 14. (A) Intraluminal mucin. (B) Extra-appendiceal mucin pools.

from patients who underwent an appendectomy between March 2002 and September 2014 at Hachioji hospital, a total of 803 patients were identified, among whom 752 had appendiceal disease. For clinicopathological analysis, appendiceal neoplasms were primarily classified according to the 2010 World Health Organization (WHO) classification (12). A total of 55 patients were excluded, including 11 with metastatic carcinoma or tumor invasion from adjacent organs, and 44 patients with a normal appendix who underwent an incidental or prophylactic appendectomy during 
Table I. Clinicopathological data of the patients with appendiceal neoplasms.

\begin{tabular}{|c|c|c|c|c|c|c|}
\hline Patient & Sex & $\begin{array}{l}\text { Age, } \\
\text { years }\end{array}$ & $\begin{array}{c}\text { Chief } \\
\text { symptom/sign }\end{array}$ & $\begin{array}{c}\text { Imaging } \\
\text { diagnosis }(\mathrm{CT} / \mathrm{US})\end{array}$ & $\begin{array}{l}\text { Preoperative } \\
\text { diagnosis }\end{array}$ & $\begin{array}{l}\text { Final pathological } \\
\text { diagnosis (depth) }\end{array}$ \\
\hline 1 & $\mathrm{~F}$ & 79 & RLQ pain & Mucinous adenocarcinoma & Appendiceal tumor & Tubular adenoma $^{a}$ \\
\hline 2 & M & 83 & RLQ pain & $\begin{array}{l}\text { Secondary appendicitis } \\
\text { caused by ileus strangulation }\end{array}$ & $\begin{array}{l}\text { Secondary appendicitis } \\
\text { caused by ileus strangulation }\end{array}$ & $\begin{array}{l}\text { Tubulovillous } \\
\text { adenoma }^{\mathrm{a}}\end{array}$ \\
\hline 3 & M & 77 & CT detection & Mucinous & Appendiceal cancer & $\begin{array}{l}\text { (Mesenchymal) } \\
\text { schwannoma }\end{array}$ \\
\hline 4 & M & 61 & RLQ pain & Acute appendicitis & Acute appendicitis & Adenocarcinoma (se) \\
\hline 5 & M & 67 & RLQ pain & Acute appendicitis & Acute appendicitis & Adenocarcinoma (mp) \\
\hline 6 & $\mathrm{~F}$ & 59 & CEA elevation & Mucinous tumor & Appendiceal tumor & $\begin{array}{l}\text { Mucinous } \\
\text { adenocarcinoma (se) }\end{array}$ \\
\hline 7 & M & 78 & PET detection & Appendiceal tumor & Appendiceal cancer & $\begin{array}{l}\text { Mucinous } \\
\text { adenocarcinoma }(\mathrm{m})^{\mathrm{a}}\end{array}$ \\
\hline 8 & $\mathrm{~F}$ & 79 & $\begin{array}{l}\text { Right lower } \\
\text { abdominal mass }\end{array}$ & Mucinous adenoma & Mucinous adenoma & $\begin{array}{l}\text { Mucinous } \\
\text { adenocarcinoma }(\mathrm{m})^{\mathrm{a}}\end{array}$ \\
\hline 9 & $\mathrm{~F}$ & 85 & $\begin{array}{l}\text { Abdominal mass, } \\
\text { fever }\end{array}$ & PMP & PMP & $\begin{array}{l}\text { Mucinous } \\
\text { adenocarcinoma (PMP) }\end{array}$ \\
\hline 10 & $\mathrm{~F}$ & 60 & RLQ pain & Acute appendicitis (abscess) & $\begin{array}{l}\text { Acute appendicitis } \\
\text { (perforated) }\end{array}$ & LAMN \\
\hline 11 & M & 77 & RLQ pain & Acute appendicitis (abscess) & $\begin{array}{l}\text { Acute appendicitis } \\
\text { (perforated, abscess) }\end{array}$ & LAMN \\
\hline 12 & $\mathrm{~F}$ & 71 & Epigastralgia & Mucinous adenoma & Mucinous adenoma & LAMN \\
\hline 13 & $\mathrm{~F}$ & 71 & RLQ pain & Acute appendicitis & Acute appendicitis & LAMN \\
\hline 14 & M & 80 & RLQ pain & $\begin{array}{l}\text { Perforated appendiceal } \\
\text { diverticulitis (free air) }\end{array}$ & $\begin{array}{l}\text { Perforated appendiceal } \\
\text { diverticulitis }\end{array}$ & LAMN (PMP) \\
\hline 15 & M & 86 & RLQ pain & Acute appendicitis & Acute appendicitis & LAMN \\
\hline 16 & M & 36 & RLQ pain & Acute appendicitis (phlegmon) & Acute appendicitis & G1 NET \\
\hline 17 & M & 43 & RLQ pain & Acute appendicitis & Acute appendicitis & MANEC (ss) \\
\hline
\end{tabular}

antramucosal neoplasm. CT, computed tomography; US, ultrasonography; F, female; M, male; RLQ, right lower quadrant; se, serosa; mp, muscularis propria; CEA, carcinoembryonic antigen; PET, positron emission tomography; $\mathrm{m}$, mucosa; PMP, pseudomyxoma peritonei; LAMN, low-grade appendiceal mucinous neoplasm; G1 NET, grade 1 neuroendocrine tumor; ss, subserosa.

surgery for other diseases, such as hemicolectomy/ileocecal resection for cecal cancer, diverticular disease or at the patient's request. Also, single center cases of material from The Tokai University Hachioji Hospital (Tokyo, Japan) were investigated.

Pathological examination. The resected appendiceal lesions were routinely fixed with $10 \%$ neutral buffered formalin, embedded in paraffin, and cut into $3-\mu \mathrm{m}$ thick sections that were stained with hematoxylin and eosin. For the present study, 2 expert pathologists and a clinician reviewed the slides. Appendiceal neoplasms (1-22 slides per case) were classified as benign (adenoma, dysplasia or mesenchymal tumor) or malignant [G1-G3 neuroendocrine tumor (NET), adenocarcinoma, mucinous adenocarcinoma, mixed adenoneuroendocrine carcinoma (MANEC) arising from pre-existing goblet cell carcinoid $(13,14)$ or low-grade appendiceal mucinous neoplasm (LAMN)]. As mucinous adenocarcinomas exhibit infiltration or invasion with fibrous desmoplasia, tumors that featured complex epithelial proliferation (complex papillary fronds and cribriform glandular spaces) or high-grade cytological atypia (full-thickness nuclear stratification, vesicular/prominent nuclei, and mitotic activity) and infiltration with fibrous desmoplasia were classified as mucinous adenocarcinomas (Fig. 1).

Conversely, tumors that exhibited minimal architectural complexity (villiform, flat epithelial proliferation and focal papillary excrescences) and low-grade cytologic atypia (mild nuclear enlargement, nuclear stratification, rare mitotic figures and single cell necrosis) were classified as LAMN (Fig. 2A). LAMN may be a precursor to low-grade pseudomyxoma peritonei (12), although its biological behavior is ambiguous; therefore, these tumors were classified separately according to the Japanese Society for Cancer of the Colon and Rectum classification, although they were also included as adenocarcinomas based on the 2010 WHO classification $(12,13,15)$.

Pseudomyxoma peritonei accompanying mucinous adenocarcinoma or LAMN were also identified. Peritoneal tumors composed of atypical glands in desmoplastic stroma or tumors 
Table II. Age distribution of patients with appendiceal neoplasms $(n=17)$.

Age range, years

\begin{tabular}{|c|c|c|c|c|c|c|c|c|}
\hline Diagnosis & Code & $30-39$ & $40-49$ & $50-59$ & $60-69$ & $70-79$ & $80-89$ & Incidence \\
\hline \multicolumn{9}{|l|}{ Benign } \\
\hline Tubular adenoma & $8211 / 0$ & & & & & & & 5.9 \\
\hline Tubulovillous adenoma & $8263 / 0$ & & & & & & 1 & 5.9 \\
\hline Mesenchymal schwannoma & $9570 / 0$ & & & & & 1 & & 5.9 \\
\hline \multicolumn{9}{|l|}{ Malignant } \\
\hline Adenocarcinoma (MOD) & $8140 / 3$ & & & & 1 & & & 5.9 \\
\hline Adenocarcinoma (papillary and MOD) & $8140 / 3$ & & & & 1 & & & 5.9 \\
\hline Mucinous adenocarcinoma (with PMP) & $8480 / 3$ & & & 1 & & 2 & 1 & 17.7 \\
\hline Low grade appendiceal neoplasm (with PMP) & $8480 / 1$ & & & & 1 & 3 & 2 & 41.2 \\
\hline Grade 1 neuroendocrine tumor (carcinoid) & $8240 / 3$ & 1 & & & & & & 5.9 \\
\hline Mixed adenoneuroendocrine carcinoma & $8244 / 3$ & & 1 & & & & & 5.9 \\
\hline
\end{tabular}

Codes are the corresponding International Classification of Disease for Oncology-3 code for that neoplasm. PMP, pseudomyxoma peritonei; MOD, moderately differentiated.

A

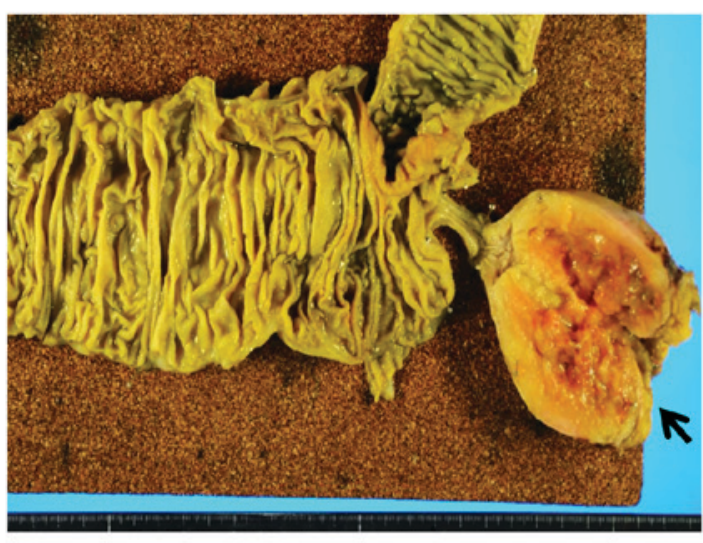

C

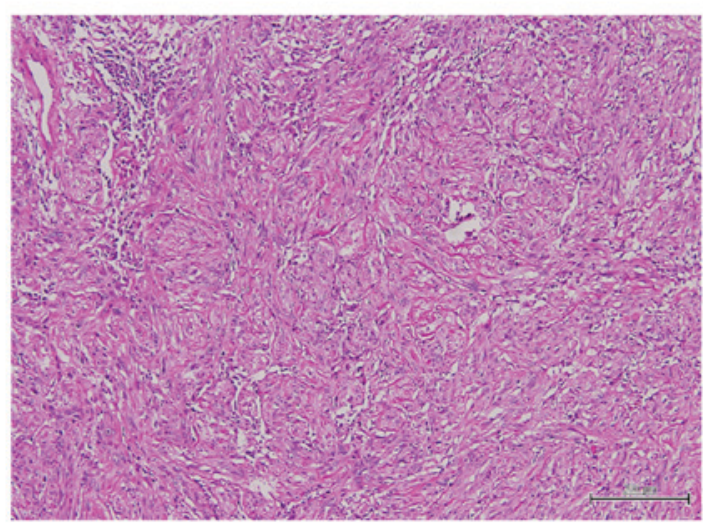

B

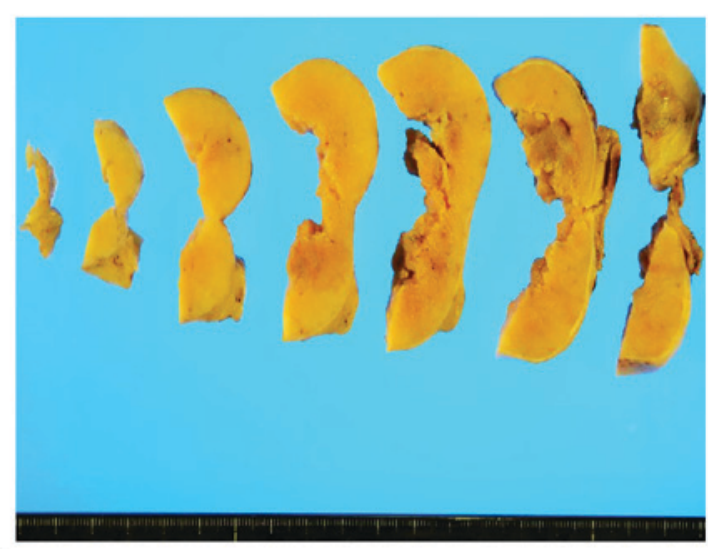

D

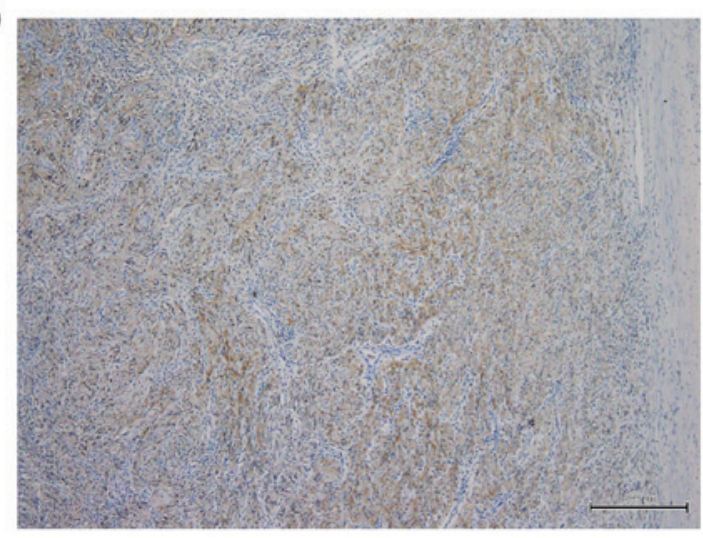

Figure 3. Representative case of a schwannoma from patient 3. (A) Resected bowel tumor (as indicated by the arrow). (B) Bowel tumor cut into slices. (C) Histological findings. (D) Immunohistochemistry for S-100 protein expression.

with high cellularity and cytological atypia containing pools of mucin were classified as mucinous adenocarcinoma-associated pseudomyxoma peritonei (high-grade; Fig. 1C) (12), whereas tumors composed of mucinous epithelium with low-grade atypia and containing mucin pools were classified as LAMN-associated pseudomyxoma peritonei (low-grade; Fig. 2B) (12). Acellular mucinosis were not categorized as an appendiceal neoplasms, but rather as a secondary lesion as mucocele is a descriptive term, according to the $2010 \mathrm{WHO}$ classification (12). 
A

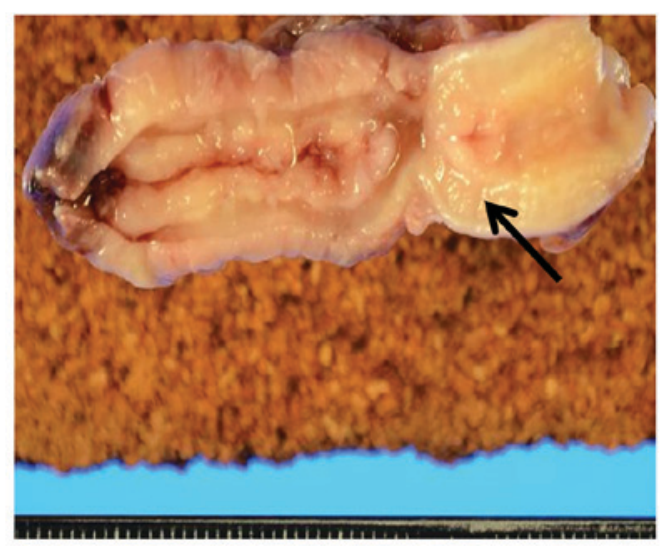

C

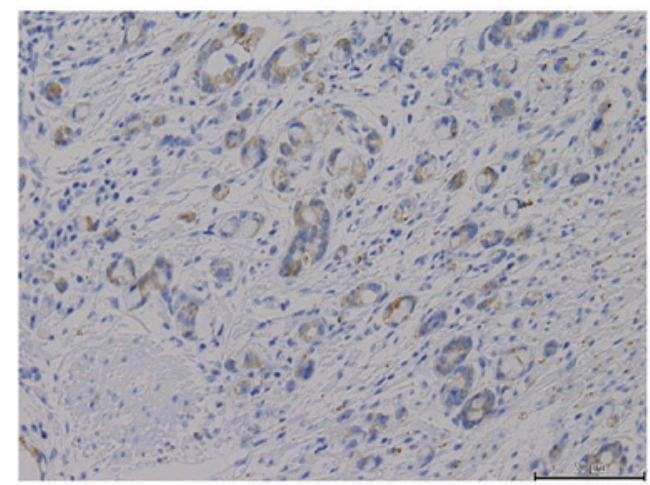

B

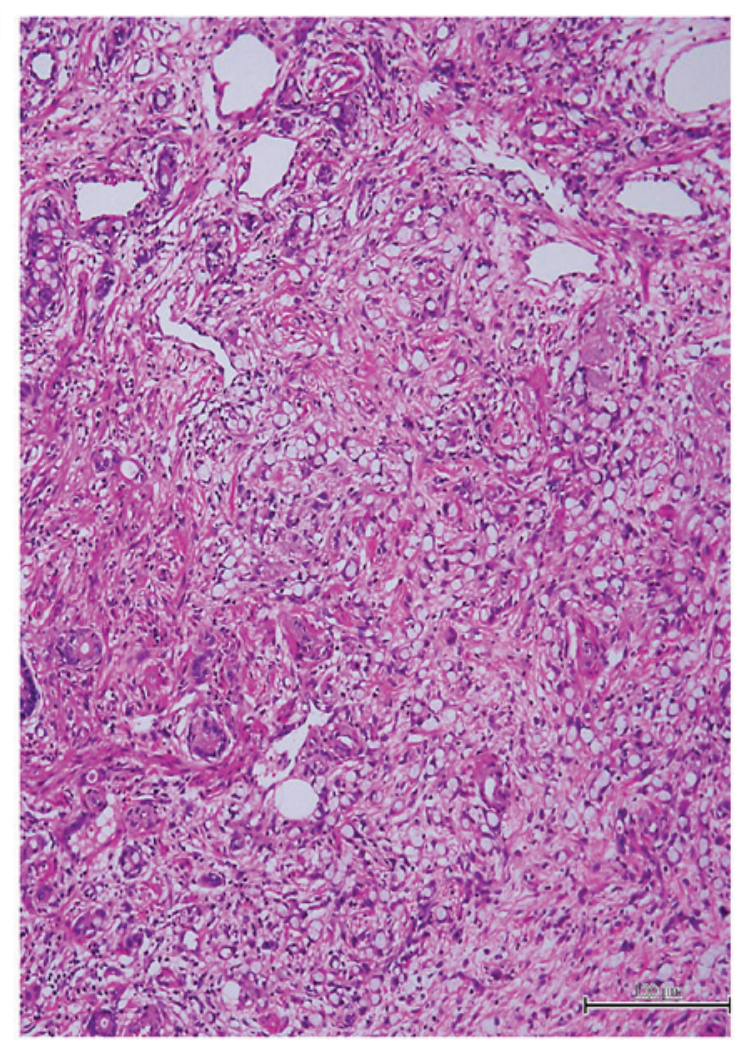

Figure 4. Representative case of a mixed adenoneuroendocrine carcinoma of the appendix from patient 17. (A) Macroscopic appearance. (B) Histological findings. (C) Immunohistochemistry for synaptophysin protein expression.

Variables assessed. The variables for evaluation included the age and sex of the 752 patients, the initial surgical findings (neoplasm or inflammation), and the age and sex of the patients grouped according to the 2 basic lesion types. The present study focused on the pathological characteristics of the appendiceal neoplasms and the clinical characteristics of the patients with these neoplasms. In this group of patients, the presenting symptoms, imaging diagnosis, preoperative diagnosis, and the types and incidence of appendiceal lesions determined by postoperative pathological examination were also reviewed. Special note was made of the intramucosal lesion types.

Statistical analysis. Patients with appendiceal neoplasms were divided into two groups aged $<60$ and $\geq 60$ years, and the difference in the incidence of appendiceal neoplasms was analyzed by the Mann-Whitney $U$ and $\chi^{2}$ tests. All statistical analyses were performed with SPSS 21.1 (IBM Corp., Armonk, $\mathrm{NY}$, USA). $\mathrm{P}<0.05$ was considered to indicate a statistically significant difference.

\section{Results}

Patient data. The 752 patients ranged in age from 2 to 89 years, with a mean age of 34.2 years. There were 431 males and 321 females. The surgical diagnosis was inflammation (appendicitis) in 735 patients $(97.7 \%)$, and appendiceal neoplasm in 17 patients $(2.3 \%)$.

Appendiceal neoplasms. The profiles of the 17 patients with appendiceal neoplasms are included in Table I, whereas the age-specific distribution of the histologic diagnoses are included in Table II. The 17 patients ranged in age from 36 to 86 years, with a mean age of 77.0 years. There were 10 men and 7 women. The majority of the appendiceal neoplasms were identified in patients aged $\geq 60$ years $(14 / 17,82.3 \%)$, and there was a significant difference in incidence between patients aged $\geq 60$ years and those aged $<60$ years $(\mathrm{P}<0.001)$. The chief presenting symptom of the majority of patients with an appendiceal neoplasm was right lower quadrant pain $(n=11,64.7 \%)$. A total of 2 patients $(11.7 \%$ ) presented with an abdominal mass, 1 patient $(5.88 \%)$ had generalized abdominal discomfort, and 3 patients $(17.6 \%)$ had no symptoms. In these 3 patients, the appendiceal neoplasm was identified with the investigation of elevated serum tumor markers, such as carcinoembryonic antigen, or incidentally by PET/CT or preoperative workup for gastric cancer. The tumor was benign in 3 patients (17.6\%) and malignant in 14 patients $(82.3 \%)$. In the 3 patients with benign disease, the preoperative clinical diagnosis was appendiceal tumor, appendiceal cancer, and secondary appendicitis caused by ileus strangulation, respectively. In the 14 patients with malignancy, the preoperative clinical diagnosis was appendicitis $(n=8,57.1 \%)$, perforated appendiceal diverticulitis $(n=1$, $5.88 \%)$ or appendiceal neoplasm $(n=5,35.3 \%)$.

The 3 benign neoplasms included 1 tubular adenoma, 1 tubulovillous adenoma, and 1 mesenchymal schwannoma (Fig. 3). The 14 malignant neoplasms included 6 adenocarcinomas (4 mucinous adenocarcinomas, 1 papillary adenocarcinoma and 1 moderately differentiated adenocarcinoma), 1 MANEC (Fig. 4), 1 neuroendocrine tumor (G1), and 6 LAMNs (1 with low-grade pseudomyxoma peritonei). One malignant tumor 
was associated with high-grade pseudomyxoma peritonei. None of the cases were considered discordant, i.e., there were no low-grade appendiceal tumors combined with high-grade peritoneal tumors. A total of $4(23.5 \%)$ of the lesions were intramucosal neoplasms, including adenomas and in situ carcinomas (patients 1, 2, 7, and 8).

Inflammation (appendicitis). The 735 patients with appendicitis ranged in age from 2 to 89 years, with a mean age of 28.0 years. They included 421 males and 314 females. Appendicitis was catarrhal in 80 patients (10.9\%), phlegmonous in 352 patients $(47.9 \%)$, and gangrenous in 268 patients $(36.5 \%)$. A total of 26 patients $(3.5 \%)$ had chronic inflammatory appendicitis that had not resolved with antibiotic treatment, 8 patients (1.1\%) had appendiceal diverticulitis and 1 patient $(0.1 \%)$ had an underlying Entamoeba histolytica infection. Almost half (43.1\%) of the patients with appendicitis were $<10$ years old. Seven of these young patients had gangrenous appendicitis, and $6(85.5 \%)$ of those 7 patients were under 4 years of age. More than half $(63.7 \%)$ of the patients with gangrenous appendicitis were over 60 years old.

\section{Discussion}

Recent trends in appendiceal pathology in patients undergoing appendectomy at our institution in Japan were investigated, particularly whether there was an increase in the incidence of appendiceal neoplasms over time. During the period from March 2002 through September 2014, the incidence of appendiceal neoplasms among patients undergoing appendectomy was $2.3 \%$. This was 3 times higher than the incidence of $0.7 \%$ reported $\sim 50$ years ago by Collins et al (16) and was $\sim 5$ times higher than the incidence reported at other Japanese institutions $(0.05 \%)$ (14). The majority $(23.5 \%)$ of the appendiceal neoplasms identified in the patients were intramucosal neoplasms, including adenoma or noninvasive carcinoma (15). Historically, these appendiceal lesions have been difficult to detect by diagnostic imaging (radiography/ultrasonography) alone (16-18). Until the 1990s, the decision to perform appendectomy was based on the patient's symptoms, findings on physical examination (especially palpation) and evidence of infection (elevation of the white blood cell count or C-reactive protein) (19-21). An appendectomy was not typically performed in the absence of symptoms, as abdominal imaging was not widely practiced at that time.

The results of the present study suggest that the relatively recent increase in the application of newer imaging modalities for the diagnosis and health screening of appendiceal diseases has led to the increased identification of asymptomatic appendiceal neoplasms. The sensitivity of these diagnostic methods has caused the detection of appendiceal neoplasms to increase (22).

The majority (64.7\%) of the patients in the present study with mucosal appendiceal neoplasms were aged $\geq 60$ years, which is similar to the age to patients with colon cancer $(6,23)$. It is generally accepted that the incidence of colon cancer has increased in Japan due to the aging of the population and the adoption of an increasingly westernized diet $(24,25)$. By analyzing the age-adjusted mortality and diagnosis rates for colon cancer in Japan. It has been confirmed that the incidence rate of colon cancer approximately doubled over the 40-year period from 1960 to 1999 (from 22-53 per 100.000 people) (23). Since 1999, the incidence rate of colon cancer has remained the same (23). As the appendix and colon develop from the midgut (26), it seems reasonable that an increased incidence of colon cancer would coincide with an increase in appendiceal neoplasms (20). This may explain the increased incidence of appendiceal neoplasms among patients undergoing appendectomy at our hospital.

Although Collins et al (16) and Connor et al (27) reported that over half (51-57\%) of the appendiceal neoplasms detected at appendectomy were carcinoid tumors (G1 NET), intramucosal neoplasms accounted for $23.5 \%$ of the appendiceal neoplasms in the patients included in the present study, and this is similar to previous Asian reports, including from Korea and Taiwan $(2,18)$. Therefore, the major types of appendiceal lesions may be influenced by geographic and ethnic factors, culminating in epidemiological differences between Asian and Western populations.

It can be difficult to precisely diagnose an appendiceal neoplasm from imaging findings prior to surgery. Therefore, pathological examination of the resected appendix is important to determine whether a lesion is benign or malignant, in addition to the depth of invasion and vascular invasion (19). Therefore, a sufficiently detailed examination should be conducted, including a consideration of whether additional resection is necessary (19). The relatively recent increased application of newer imaging modalities to diagnosis and health screening may have led to the increased identification of asymptomatic appendiceal neoplasms (22). A number of studies have indicated that the incidence of necrotic and penetrating appendicitis is higher in pediatric and elderly populations (28-30).

In conclusion, the findings of the present study indicate that the incidence of appendiceal neoplasms is increasing. Accordingly, surgeons should be aware of the possibility of these entities, particularly in patients aged $\geq 60$ years, due to the frequent occurrence of malignant and potentially malignant neoplasms in appendectomy materials $(2.3 \%, \sim 3-5$ times higher than previously reported). In addition, the frequent preoperative diagnosis of appendicitis in patients with appendiceal neoplasms $(57.1 \%)$ and characteristic age distribution of patients with gangrenous appendicitis $(\leq 4,85.5 \%$; $\geq 60,63.7 \%)$ as demonstrated in the present study.

\section{Acknowledgements}

The authors would like to thank the staff at the Department of Diagnostic Pathology of The Tokai University Hachioji Hospital for their technical assistance and insightful comments.

\section{Funding}

Not applicable.

\section{Availability of data and materials}

The datasets used and/or analyzed during the current study are available from the corresponding author on reasonable request. 


\section{Authors' contributions}

TakaT designed and performed the research for the present study, contributed to the analysis and wrote the present manuscript. TakuT designed the research for the present study, provided pathological advice and supervised the present study. TS contributed to analysis and interpretation of data in the pathological field. SH, SY, HS and SS contributed to analysis and interpretation of data in the surgical field. MM and HM contributed to analysis and interpretation of data and assisted in the preparation of the manuscript.

\section{Ethics approval and consent to participate}

The present study was approved by the institutional review board of Tokai University Hachioji Hospital (approval no. R14-242). Written informed consent for the appendectomy was obtained from the patients and/or family members.

\section{Consent for publication}

Written informed consent for publication of the present study was obtained from the patients and/or family members.

\section{Competing interests}

The authors declare that they have no conflicts of interest.

\section{References}

1. Deans GT and Spence RA: Neoplastic lesions of the appendix. Br J Surg 82: 299-306, 1995.

2. Lee WS, Choi ST, Lee JN, Kim KK, Park YH and Baek JH: A retrospective clinicopathological analysis of appendiceal tumors from 3,744 appendectomies: A single-institution study. Int J Colorectal Dis 26: 617-621, 2011.

3. Rao PM, Rhea JT, Rattner DW, Venus LG and Novelline RA: Introduction of appendiceal CT: Impact on negative appendectomy and appendiceal perforation rates. Ann Surg 229: 344-349, 1999.

4. Chung DS, Kang S and Park JB: Incidental finding of appendiceal adenocarcinoma in F-18 FDG PET/CT for health screening. Nucl Med Mol Imaging 46: 308-310, 2012.

5. Arai T, Kanazawa K, Sakurai U, Sawabe M, Tei S, Honma N, et al: Pathology of appendiceal disease. Gastrointestinal pathology 11. lower intestine. Pathol Clin Med 29: 1105-1113, 2011 (In Japanese)

6. Ishihara H, Kataoka M, Hasegawa K, Nakayama H, Takeda S and Kondo K: A case of appendiceal mucinous cystadenoma in persistent appendix. J Jpn Surg Assoc 74: 3073-3076, 2013 (In Japanese).

7. Aida N, Jingu K, Uematsu T and Kitabayashi H: A case report of mucinous cystadenocarcinoma arising from the incision scar of appendectomy for appendicitis 46 years after surgery. J Jpn Surg Assoc 74: 3077-3081, 2013 (In Japanese).

8. Tamura J, Kitagawa K, Ura K and Baba N: A case of multiple colon perforation caused by fulminant amoebic colitis associated with HIV infection. Rinshogeka 64: 993-997, 2009 (In Japanese).

9. Okamoto M, Oohata K, Sasahira N, Yoshida H, Hada T, Katamoto T, Yamaji Y, Kawabe T and Omata M: Three cases of amebic colitis detected by positive fecal occult blood test in mass screening. Prog Dig Endosc 61: 106-107, 2002 (In Japanese).

10. Miyasaka Y, Yasui D, Nakagawa M, Watanabe M and Doi F: A case of acute amebic appendicitis. Shokakigeka 28: 503-506, 2005 (In Japanese).

11. Iwashita A, Yamada Y, Yao K, Arita M, Takasaki J and Tsuda S: Clinicopathological study on 2,169 appendices. Ito Cho 10: 1185-1194, 1990 (In Japanese).
12. Carr NJ, Sobin LH, Komminoth P, Arnold R, Cappela C, Klimstra DS, et al: Tumours of the appendix. In: WHO Classification of Tumours of the Digestive System. Bosman TF, Carneiro F, Hruban RH, Theise ND (eds). 4th edition. International Agency for Research on Cancer (IARC), Lyon, pp119-129, 2010.

13. Rindi G, Arnold R, Bosman FT, Capella C, Klimstra DS, Kloppel G, Paul Komminoth and Solcia E: Nomenclature and classification of neuroendocrine neoplasms of the digestive system. In: Bosman TF, Carneiro F, Hruban RH, Theise ND, editors. WHO Classification of Tumours of the Digestive System, 4th ed. Lyon: International Agency for Research on Cancer (IARC) pp. 13-14, 2010

14. Ozawa H, Moritani K, Wada O, Fujita S and Kotake K: Statistics of appendiceal malignant tumors: Data from the JSCCR registry and the Japan autopsy annual database. Stomach and Intestine (Tokyo) 49: 495-499, 2014 (in Japanese).

15. Japanese Society for Cancer of the Colon and Rectum (JSCCR): General rules for Clinical and Pathological Studies on Cancer of the Colon, Rectum and Anus. 8th edition. Kanehara Shuppan, Tokyo, 2013.

16. Collins DC: 71,000 human appendix specimens. A final report, summarizing forty years' study. Am J Proctol 14: 265-281, 1963.

17. Matsuda K, Tsukamoto M, Fukushima Y, Akahane T, Horiuchi A, Shimada R, Nakamura K, Tsuchiya T, Hayama T, Yamada $\mathrm{H}$, et al: Clinical features and treatment principles of appendiceal cancers. Stomach and Intestine (Tokyo) 49: 509-519, 2014 (In Japanese).

18. Pickhardt PJ, Levy AD, Rohrmann CA Jr and Kende AI: Primary neoplasms of the appendix: Radiologic spectrum of disease with pathologic correlation. Radiographics 23: 645-662, 2003.

19. Chen HT, Lee YT, Chou AS, Wu YK, Yin WY, Lee MC and Hsu YH: Primary appendiceal malignancy: A clinicopathologic study. Kaohsiung J Med Sci 22: 618-625, 2006.

20. Lewis FR, Holcroft JW, Boey J and Dunphy JE: Appendicitis. A critical review of diagnosis and treatment in 1,000 cases. Arch Surg 110: 677-684, 1975.

21. Jess P, Bjerregaard B, Brynitz S, Holst-Christensen J, Kalaja E and Lund-Kristensen J: Acute appendicitis. Prospective trial concerning diagnostic accuracy and complications. Am J Surg 141: 232-234, 1981.

22. Izbicki JR, Knoefel WT, Wilker DK, Mandelkow HK, Müller K, Siebeck M and Schweiberer L: Accurate diagnosis of acute appendicitis: A retrospective and prospective analysis of 686 patients. Eur J Surg 158: 227-231, 1992.

23. Health and Welfare Statistics Association: J Health Welfare Stat Tokyo 61: 63-67, 2014/2015 (In Japanese).

24. Kolonel LN, Hinds MW and Hankin JH: Cancer patterns among migrant and native-born Japanese in Hawaii in relation to smoking, drinking and dietary habits. In: Genetic and Environmental Factors in Experimental and Human Cancer. Gelboin HV, Mac Mahon B, Matsushima T, Sugimura T, Takayama S and Takebe H (Eds). Japan Scientific Societies Press, Tokyo, pp327-340, 1980 .

25. Maskarinec G and Noh JJ: The effect of migration on cancer incidence among Japanese in Hawaii. Ethn Dis 14: 431-439, 2004.

26. Lunniss PJ, Stringer MD and Standring S: Gray's anatomy: The anatomical basis of medicine and surgery. Elsevier, pp1136-1159, Philadelphia, 2016.

27. Connor SJ, Hanna GB and Frizelle FA: Appendiceal tumors: Retrospective clinicopathologic analysis of appendiceal tumors from 7,970 appendectomies. Dis Colon Rectum 41: 75-80, 1998.

28. Kawashima H, Iwanaka T, Arai M, Kudo S, Fujishiro J and Imaizumi S: Clinical analysis of timing of laparoscopic appendectomy for appendicitis in children. J Jpn Soc Emer Ped (JJSEP) 2: 31-34, 2003 (In Japanese).

29. Watanabe S, Watanabe A and Fukuda C: Diagnosis of childhood perforated appendicitis and active observation of suspected appendicitis. J Jpn Soc Emer Ped (JJSEP) 2: 25-29, 2003 (In Japanese).

30. Zbierska K, Kenig J, Lasek A, Rubinkiewicz M and Wałęga P: Differences in the clinical course of acute appendicitis in the elderly in comparison to younger population. Pol Prezegl Chir 88: 142-146, 2016.

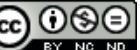

This work is licensed under a Creative Commons Attribution-NonCommercial-NoDerivatives 4.0 International (CC BY-NC-ND 4.0) License. 